\title{
Dynamic evolution of the fractures and hydraulic pressures in water-resistant strata between karst cavity and tunnel based on discrete element method
}

\author{
Zhenyu He $\mathrm{He}^{1, \mathrm{a}}$, Jiaqi Guo ${ }^{1,2, \mathrm{~b}}$, and Fan Chen ${ }^{1, \mathrm{c}}$ \\ ${ }^{1}$ School of civil Engineering, Henan Polytechnic University, Jiaozuo, Henan, 454000, China \\ 2 Laboratory of Deep Mine Construction, Henan Polytechnic University; Jiaozuo, 454000, China \\ ahezy101@163.com, bgjq519@163.com, c1228586533@qq.com
}

\begin{abstract}
Keywords: karst tunnel; large-scale karst cavity; water-inrush; discrete element method Abstract. Based on the discrete element software (UDEC), the variation laws of the seepage field and displacement field in water-resistant strata between karst cavity with high-pressuried water and tunnel are simulated and analyzed in thin limestone strata. The results show that under the same karst water pressure, when the thickness of water-resistant strata is $2 \mathrm{~m}$, the water-resistant strata is in the whole collapse tendency and the water-inrush channels are formed in a short time, but when the thickness of water-resistant strata is $4 \mathrm{~m}$, the rock mass in the $1 \mathrm{~m}$ range above the tunnel vault is slumped to form a collapse arch, which is less prone to water-inrush.
\end{abstract}

\section{Introduction}

China's vast territory, but the mountain area coverage reaches $70 \%$, and the soluble rock area is about $33 \%$ of the land area, in which the hydrogeological environment is particularly complex and changeable. Since the 21 st century, with the rapid development of infrastructure construction in China, as well as the continuous development of traffic networks, more and more deep tunnels have to cross a variety of complex geology. Especially in karst development areas, high-risk deep tunnels in the process of the construction or operation are threatened by the large-scale karst cavities. Therefore, it is of great value to study the mechanism of water-inrush in karst tunnels, which is important to prevent water inrush and ensure safe production of tunnels.

A large number of scholars have studied the influence of concealed karst cave on the stability of tunnel surrounding rock by numerical simulation, and comprehensively judge the formation of water-inrush channels according to displacement monitoring and plastic zones. Jiaqi Guo et al analyzed the expansion mechanism of high pressure karst water from the perspective of fracture mechanics [1]; and deduced the formula of the radius of plastic zone around the elliptical hole portal with the complex variable function method [2]; Liping $\mathrm{Li}$ analyzed the catastrophic process of water-inrush induced by unloading damage under strong seepage by RFPA-flow [3]; Zhanping Song researched the influence of concealed cave on the stability of circular tunnel [4]; Zhenyu He et al briefly analyzed the patterns of water-inrush in karst tunnel [5]; Mingjie Zhao et al analyzed the influence of the cavern at the top, bottom and side of the tunnel on the stability of the tunnel surrounding rock using two-dimensional elastic-plastic method by the ANSYS software [6-7]; Lin Shao et al studied the influence of different locations of kast caves on the stability of tunnel surrounding rock, and considered that the bottom cave had the greatest influence on the surrounding rock [8]. At present, there are many researches on the small-scale kast cavity, and most of them are empty caves. There is little research on the dynamic evolution of fractures and hydraulic pressures in water-resistant strata after tunnels excavation. Based on the discrete element software (UDEC), the dynamic evolution of the fissures and hydraulic pressures in water-resistant strata and the formation process of the water-inrush channels are analyzed. 


\section{Model establishment and parameters selection}

In order to analyze the catastrophic evolution process of large-scale water-filled karst cavity above the tunnel in the thin limestone strata, this paper adopts the three-circle tunnel section with height of $9.5 \mathrm{~m}$, span of $8.5 \mathrm{~m}$ and buried depth of $500 \mathrm{~m}$. And the large-scale concealed karst cavity is generalized to an ellipse with a long axis of $20 \mathrm{~m}$ and a minor axis of $12 \mathrm{~m}$. The model size is $80 \mathrm{~m} \times 80 \mathrm{~m}$, and the weight of the upper rock mass is converted into uniform load on the upper boundary of the model according to buried depth of the tunnel. The lower boundary of the model adopts the constraint displacement boundary, and the stress boundary is applied on both sides of the model, and the side pressure coefficient is 1.2. The calculation model and the arrangement of monitoring location is shown in Fig 1. The distance (d) between the tunnel and the cavity is $2 \mathrm{~m}$ and $4 \mathrm{~m}$ respectively, and the karst water pressure (p) is $2 \mathrm{MPa}$ and $5 \mathrm{MPa}$ respectively. The values of the numerical simulation parameters are shown in Table 1.

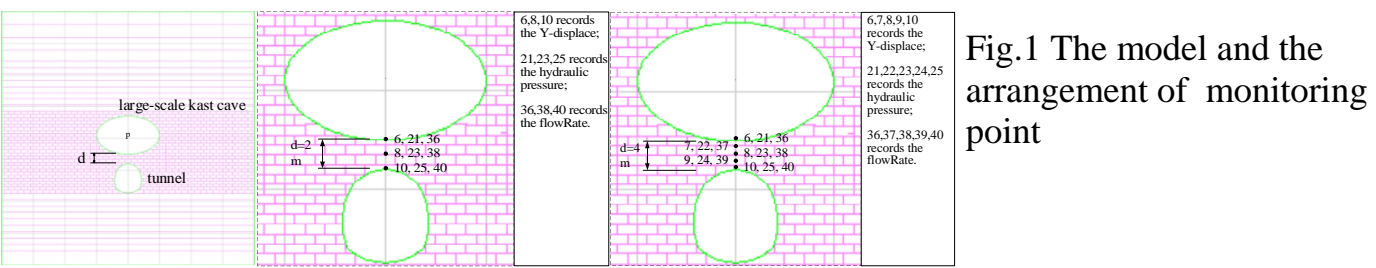

Table.1 Mechanical parameters employed in calculation

\begin{tabular}{ccccccccc}
\hline materials & $\begin{array}{c}\text { Density } \\
\left(\mathrm{kg} / \mathrm{m}^{3}\right)\end{array}$ & $\begin{array}{c}\text { elastic modulus } \\
(\mathrm{GPa})\end{array}$ & Poisson ratio & $\begin{array}{c}\text { Friction angle } \\
\left({ }^{\circ}\right)\end{array}$ & $\begin{array}{c}\text { Cohesion } \\
(\mathrm{MPa})\end{array}$ & $\begin{array}{c}\text { Internal friction } \\
\text { angle }\left({ }^{\circ}\right)\end{array}$ & $\begin{array}{c}\mathrm{K}_{\mathrm{n}} \\
\left(\mathrm{GPa} \cdot \mathrm{m}^{-1}\right)\end{array}$ & $\begin{array}{c}\mathrm{K}_{\mathrm{s}} \\
\left(\mathrm{GPa} \cdot \mathrm{m}^{-1}\right)\end{array}$ \\
\hline zones & 2.4 & 30 & 0.25 & 35 & 0.8 & -- & -- & - \\
joints & -- & -- & -- & -- & 0.5 & 33 & 180 & 144 \\
\hline
\end{tabular}

\section{Displacement field and seepage field analysis}

Case 1: The thickness of water-resistant strata is $2 \mathrm{~m}$, and water pressure is $2 \mathrm{MPa}$. In the calculation of $1 \mathrm{~s}, 5 \mathrm{~s}, 10 \mathrm{~s}$, respectively, the y-displacement and water pressure distribution of the model are shown in Fig 2. The local y-displacement and flow direction are shown in Fig 3. The displacement, water pressure and flow at the recording point within 10s are shown in Fig 4.

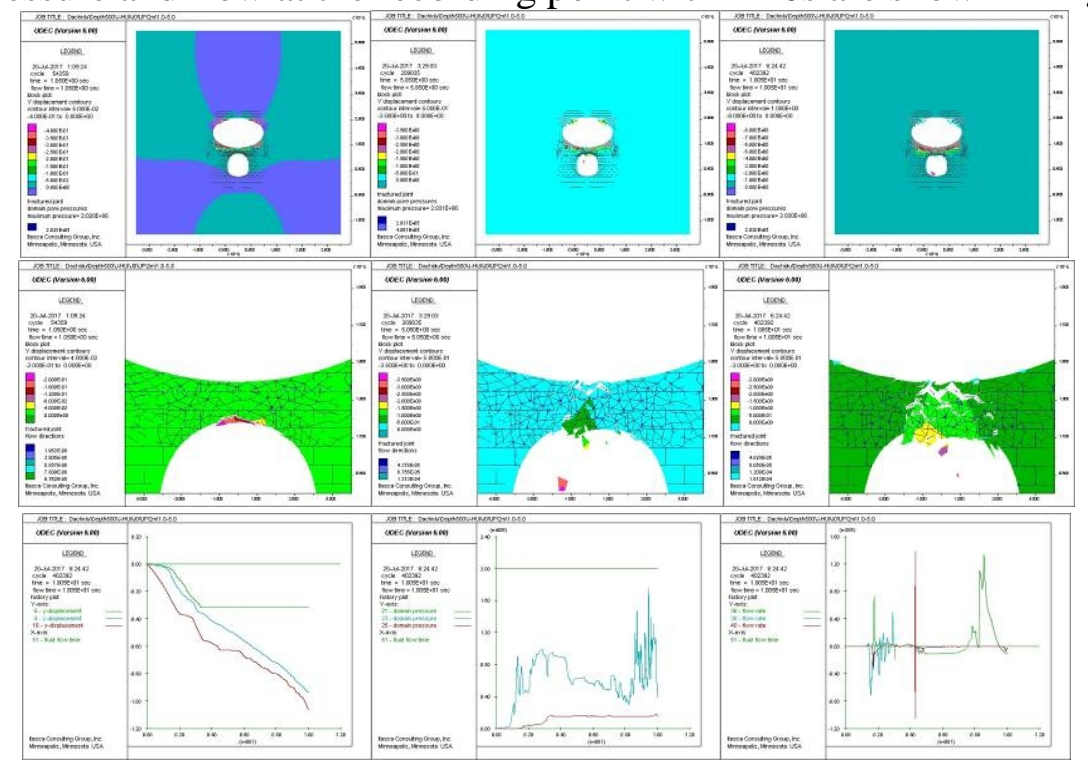

Fig. 2 In the calculation of $1 \mathrm{~s}, 5 \mathrm{~s}$, 10 s, respectively, the y-displacement and water pressure distribution of the model

Fig. 3 The local y-displacement and flow directions

Case 2: The thickness of water-resistant strata is $2 \mathrm{~m}$, and water pressure is 5MPa. Similar to Case 1, we can get Figures 5, 6, 7, respectively.

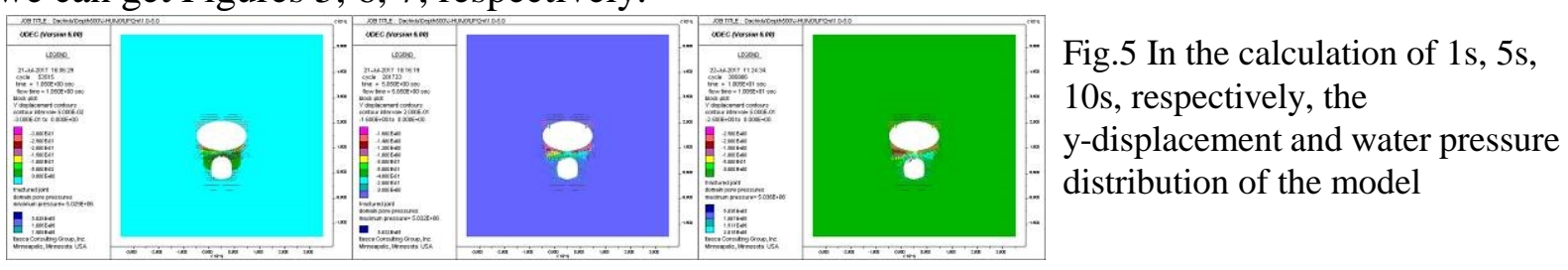




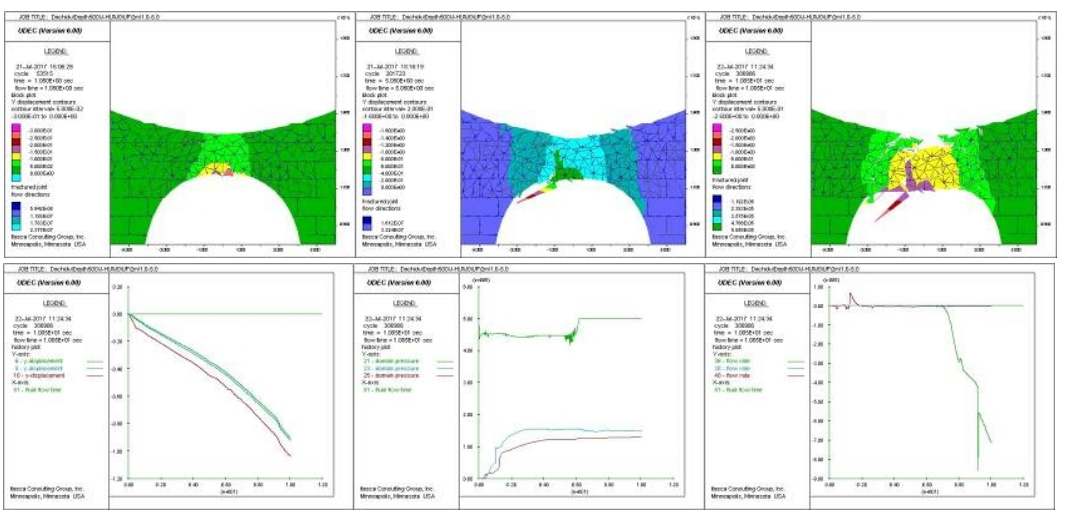

Fig.6 The local y-displacement and flow directions

Compared with the y-displacement curves in Fig.4 and Fig.7, we can see that when the thickness of the water-resistant strata is $2 \mathrm{~m}$, there is a significant overall collapse with the increase of the water pressure. According to the flow direction in Fig. 3 and Fig. 6 and the water pressure curves in Fig. 4 and Fig. 7, it can be seen that the water-inrush channels are formed in the water-resistant strata at $2 \mathrm{MPa}$ and $5 \mathrm{MPa}$ water pressure.

Case 3: The thickness of water-resistant strata is $4 \mathrm{~m}$, and water pressure is $2 \mathrm{MPa}$. Similar to Case 1, we can get Figures 8, 9, 10, respectively.

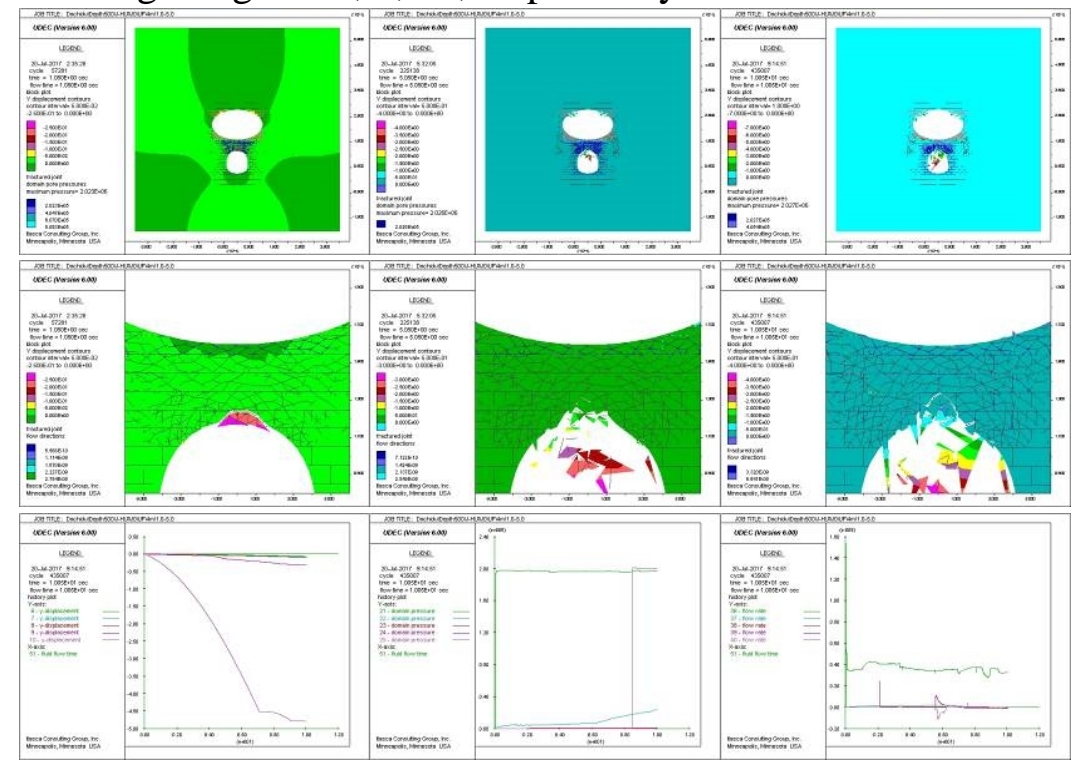

Fig. 8 In the calculation of $1 \mathrm{~s}, 5 \mathrm{~s}$, 10 s, respectively, the $\mathrm{y}$-displacement and water pressure distribution of the model

Fig.9 The local y-displacement and flow directions

Case 4: The thickness of water-resistant strata is $4 \mathrm{~m}$, and water pressure is $5 \mathrm{MPa}$. Similar to Case 1, we can get Figures 11, 12, 13, respectively.

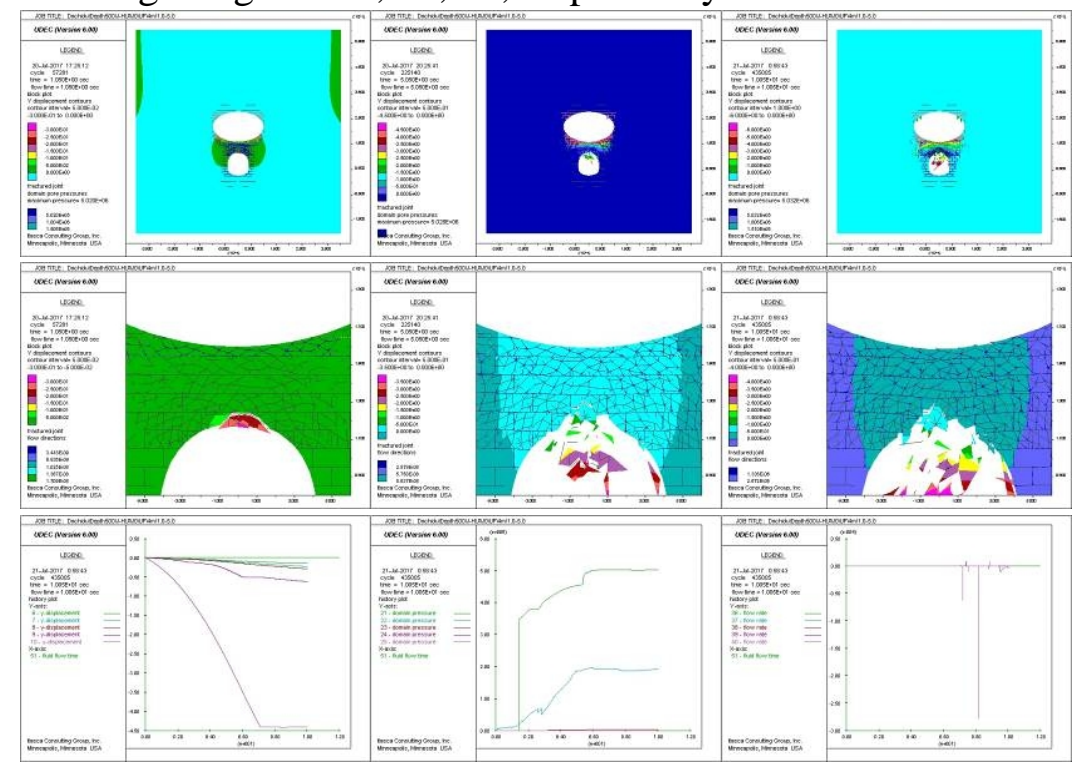

Fig.10 The displacement, water pressure and flow curves at the recording point within $10 \mathrm{~s}$

Fig. 11 In the calculation of $1 \mathrm{~s}, 5 \mathrm{~s}$, $10 \mathrm{~s}$, respectively, the $\mathrm{y}$-displacement and water pressure distribution of the model

Fig. 12 The local y-displacement and flow directions

Fig. 13 The displacement, water pressure and flow curves at the recording point within $10 \mathrm{~s}$ 
According to the y-displacement curves in Fig.10 and Fig.13 and the y-displacement clouds in Fig.9 and Fig.12, we can see that when the thickness of the water-resistant strata is $4 \mathrm{~m}$, the rock mass within $1 \mathrm{~m}$ above the tunnel collapses and forms a collapse arch, rather than the overall break like case 1 and case 2, whether the water pressure is $2 \mathrm{MPa}$ or $5 \mathrm{MPa}$. Compared with the flow directions in Fig. 9 and Fig.12 and the water pressure curves in Fig.10 and Fig.13, it can be seen that water-inrush occurs first in case 4.

\section{Conclusions}

In this paper, the failure modes of the water-resistant strata with $2 \mathrm{~m}$ and $4 \mathrm{~m}$ thickness under $2 \mathrm{MPa}$ and $5 \mathrm{MPa}$ hydraulic pressure are analyzed, respectively. And the dynamic distribution of water pressure is also discussed. Under the same karst water pressure, when the thickness of water-resistant strata is $2 \mathrm{~m}$, it will be in the whole collapse tendency and the water-inrush channels are formed in a short time. When the thickness of water-resistant strata is $4 \mathrm{~m}$, the rock mass in the $1 \mathrm{~m}$ range above the tunnel vault is slumped to form a collapse arch, which is less prone to water inrush.

\section{Acknowledgements}

This work was financially supported by the National "973" Key Basic Research Program Foundation of China (2013CB036003), National Natural Science Foundation of China (51778215), National Natural Science Foundation of China (50978018) and Henan Polytechnic University Doctoral Fund (B2012-016). This support is gratefully acknowledged.

\section{References}

[1] Jiaqi Guo and Chunsheng Qiao. Journal of the China railway Society. Vol. 35 (2013), p. 108-114 (In Chinese)

[2] Jiaqi Guo and Chunsheng Qiao. Journal of the China railway Society. Vol. 34 (2012), p. 105-111 (In Chinese)

[3] Liping Li. Study on Catastrophe Evolution Mechansim of Kast Water Inrush and its Engineering Application of High Risk Karst Tunnel [D]. Jinan: Shandong University, 2009 (In Chinese)

[4] Zhanping Song, Yanbo Qi and Ning Li. Rock and Soil Mechanics. Vol. 28 (2007), p. 485-489 (In Chinese)

[5] Zhenyu He, Jiaqi Guo, Fan Chen and Junkun Tan. The Chinese Journal of Geological Hazard and Control. Vol. 28 (2017), p. 97-107 (In Chinese)

[6] Mingjie Zhao, Xuejun Wang, Xuhua Liu, Jianhua Ao and Biao Wang. Journal of Chongqing Jianzhu University. Vol. 25 (2003), p. 6-17 (In Chinese)

[7] Mingjie Zhao, Xuhua Liu, Jianhua Ao and Biao Wang. Rock and Soil Mechanics. Vol. 24 (2003), p. 445-449 (In Chinese)

[8] Lin Shao, Yujun Zuo and Xixian Song. Chinese Journal of Underground Space and Engineering. Vol. 10 (2014), p. 51-56 (In Chinese) 